\title{
Whole genome sequence and a phylogenetic analysis of the G8P[14] group A rotavirus strain from roe deer
}

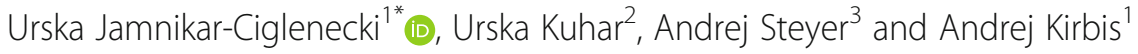

\begin{abstract}
Background: Group A rotaviruses (RVA) are associated with acute gastroenteritis in children and in young domestic and wild animals. A RVA strain was detected from a roe deer for the first time during a survey of game animals in Slovenia in 2014. A further RVA strain (SLO/D110-15) was detected from a roe deer during 2015. The aim of this study was to provide a full genetic profile of the detected RVA strain from roe deer and to obtain additional information about zoonotic transmitted strains and potential reassortments between human rotavirus strains and zoonotic transmitted rotavirus strains. The next generation sequencing (NGS) analysis on Ion Torrent was performed and the whole genome sequence has been determined together with a phylogenetic analysis.

Results: The whole genome sequence of SLO/D110-15 was obtained by NGS analyses on an lonTorrent platform. According to the genetic profile, the strain SLO/D110-15 clusters with the DS-1-like group and expresses the G8-P[14]-I2-R2-C2-M2-A3-N2-T6-E2-H3 genome constellation. Phylogenetic analysis shows that this roe deer G8P[14] strain is most closely related to RVA strains found in sheep, cattle and humans. A human RVA strain with the same genotype profile was detected in 2009 in Slovenia.
\end{abstract}

Conclusions: The G8P[14] genotype has been found, for the first time, in deer, a newly described host from the order Artiodactyla for this RVA genotype. The finding of a rotavirus with the same genome segment constellation in humans indicates the possible zoonotic potential of this virus strain.

Keywords: Group A rotavirus, Wildlife, Deer, Zoonotic transmission, Phylogenetic analysis, Next generation sequencing, NGS

\section{Background}

Group A rotaviruses (RVA) are members of the genus Rotavirus belonging to the highly diverse Reoviridae family, whose members are capable of infecting various host species (mammals, reptiles, fish, birds, fungi, plants and insects) [1]. Their genome consists of eleven double-stranded RNA segments that encode six structural proteins (VP1 to VP4, VP6 and VP7) and six nonstructural proteins (NSP1-6) [2]. From a medical and veterinary perspective, RVA is the most important member

\footnotetext{
* Correspondence: urska.jamnikar@vf.uni-lj.si

'Institute of Food safety, Feed and Environment, Veterinary Faculty,

University of Ljubljana, Gerbičeva 60, 1000 Ljubljana, Slovenia

Full list of author information is available at the end of the article
}

of the genus and is associated with acute gastroenteritis in children and in young domestic and wild animals [2-4].

The RVA are classified according to the two outer capsid proteins VP7 and VP4, and at least 35 G-types and 50 P-types [5], respectively, have been characterized in humans and animals with more than 60 G-P combinations. In order to provide a better insight into RVA diversity and evolution, a new whole genome genotyping system was established and proposed by the Rotavirus Classification Working Group (RCWG) [6]. Under this classification system, the notation $\mathrm{Gx}-\mathrm{P}[\mathrm{x}]-\mathrm{Ix}-\mathrm{Rx}-\mathrm{Cx}-$ $\mathrm{Mx}-\mathrm{Ax}-\mathrm{Nx}-\mathrm{Tx}-\mathrm{Ex}-\mathrm{Hx}$ (" $\mathrm{x}$ " denotes the genotype number) has been used to represent the complete genotype constellation (VP7-VP4-VP6-VP1-VP2-VP3-NSP1- 
NSP2-NSP3-NSP4-NSP5 genes) of a RVA strain [7]. According to the genome segments' genotype constellation, there are three main rotavirus genogroups, Wa-like (G1P[8]), DS-1-like (G2P[4]) and AU-1-like (G3P[9]), identified in humans and animals, respectively [8]. It was shown previously, that human Wa-like strains are related to porcine Wa-like strains and that human and bovine DS-1-like strains are also closely related. In addition, reports on bovine-like G6, G8 and G10 strains from the DS-1-like genogroup were frequently reported in human infections indicating the possible zoonotic transmission from animals to humans [9]. Whole genome sequencing is particularly important for the study of zoonotic transmitted strains and potential reassortments between human and animal RVA strains [10].

Rotaviruses have been reported in many ungulates, including deer [11], but only a few genomes of these RVA strains have been studied. Until recently, there have been no reports describing the genomes of RVA strains in deer. In our previous report [12], the first genome of the roe deer RVA strain was described as having the G6-P[15]-I2-R2-C2-M2-A3-N2-T6-E2-H3 genotype constellation. Later that year a red deer RVA strain from the USA with G8-P[1]-I2-R2-C2-M2-A3-N2-T6-E2-H3 was reported [13]. These two strains share the same bovine DS1-like genetic backbone but have different G/P combinations. Here we report a second roe deer RVA strain with the genotype constellation G8-P[14]-I2-R2-C2-M2-A3N2-T6-E2-H3.

\section{Methods}

\section{Sample collection and molecular detection of RVA}

Initial findings from a survey conducted in 2014 and 2015 to screen certain game animals as a potential source of rotaviruses have previously been reported [12]. Screening of a further 15 samples from roe deer using specific RT-PCR and real-time RT-PCR [12] identified a further RVA-positive sample (SLO/D110-15). The sample was collected in October 2015, in Lahovče (hunting family Krvavec) from a one-year-old roe deer of

Table 1 Genome genotype constellation of the 11 segments of RVA/Roe deer-wt/SLO/D110-15/G8P[14], the closest nucleotide identities from GenBank and identities shared with Slovenian RVA/Hu-wt/SVN/SI-2987/09/G8P[14] strain

\begin{tabular}{|c|c|c|c|c|c|c|}
\hline \multirow[t]{2}{*}{ Gene } & \multicolumn{2}{|c|}{ Strain SLO/D110-15 } & \multicolumn{4}{|c|}{ Strains in the GenBank with the closest nucleotide identity } \\
\hline & Genotype & Accession no. & Strain & Accession no. & Nt identity (\%) & Host \\
\hline \multirow[t]{2}{*}{ VP7 } & G8 & KY426808 & OVR762 & EF554153 & 96.9 & Ovine \\
\hline & & & SI-2987/09 & KY972333 & $85.7^{\mathrm{a}}$ & Human \\
\hline \multirow[t]{2}{*}{ VP4 } & $P[14]$ & KY426812 & Tottori-SG & AB853893 & 94.7 & Bovine \\
\hline & & & SI-2987/09 & KY972331 & $83.7^{\mathrm{a}}$ & Human \\
\hline \multirow[t]{2}{*}{ VP6 } & 12 & KY426813 & Tottori-SG & AB853894 & 94.1 & Bovine \\
\hline & & & SI-2987/09 & KY972332 & $87.0^{\mathrm{a}}$ & Human \\
\hline \multirow[t]{2}{*}{ VP1 } & R2 & KY426809 & B10925 & EF554115 & 94.8 & Human \\
\hline & & & SI-2987/09 & KY972328 & $85.5^{\mathrm{a}}$ & Human \\
\hline \multirow[t]{2}{*}{ VP2 } & $\mathrm{C} 2$ & KY426810 & $182-02$ & KU508381 & 92.3 & Human \\
\hline & & & SI-2987/09 & KY972329 & $95.4^{\mathrm{a}}$ & Human \\
\hline \multirow[t]{2}{*}{ VP3 } & M2 & KY426811 & SI-R56 & JX094030 & 98.6 & Human \\
\hline & & & SI-2987/09 & KY972330 & $91.1^{a}$ & Human \\
\hline \multirow[t]{2}{*}{ NSP1 } & A3 & KY426803 & NCDV & GU808570 & 97.2 & Bovine \\
\hline & & & SI-2987/09 & KY972323 & $99.7^{\mathrm{a}}$ & Human \\
\hline \multirow[t]{2}{*}{ NSP2 } & N2 & KY426804 & 1604 & JN831216 & 96.6 & Bovine \\
\hline & & & SI-2987/09 & KY972324 & $99.3^{\mathrm{a}}$ & Human \\
\hline \multirow[t]{2}{*}{ NSP3 } & T6 & KY426805 & UCD & GQ428138 & 97.8 & Giraffe \\
\hline & & & SI-2987/09 & KY972325 & $93.1^{\mathrm{a}}$ & Human \\
\hline \multirow[t]{2}{*}{ NSP4 } & E2 & KY426806 & BEF06018 & KU128901 & 97.8 & Human \\
\hline & & & SI-2987/09 & KY972326 & $97.0^{a}$ & Human \\
\hline \multirow[t]{2}{*}{ NSP5 } & $\mathrm{H} 3$ & KY426813 & BEF06018 & KU128902 & 99.7 & Human \\
\hline & & & SI-2987/09 & KY972327 & $95.1^{\mathrm{a}}$ & Human \\
\hline
\end{tabular}


appropriate weight for its age and exhibiting no specific clinical signs.

\section{RNA extraction, NGS and analysis of sequence reads}

To determine the whole genome of the RVA strain SLO/ D110-15, the sample was prepared for the NGS. Total RNA was extracted with Trizol reagent (Invitrogen, Carlsbad, USA) in combination with the RNeasy Mini Kit (Qiagen, Hilden, Germany), using the protocol with on-column DNase I digestion according to the manufacturer's instructions. The RNA was used as the template for cDNA synthesis with the cDNA Synthesis System (Roche, Manheim, Germany) according to the Genome Sequencer Rapid RNA library protocol (Roche). The cDNA was fragmented with a Covaris M220 focused ultrasonicator, targeting peak fragments with lengths of 200-300 bp. The fragmented cDNA was used for library preparation using GeneRead DNA Library L Core Kit (Qiagen,
Hilden, Germany). Purification and size selection of the library were performed with Ampure XP magnetic beads (Beckman Coulter, Brea, CA, USA). The library was quantified with the GeneRead Library Quant Kit (Qiagen, Hilden, Germany) and a Qubit 3.0 fluorometer (Thermo Fisher Scientific, Carlsbad, CA, USA). Emulsion PCR and enrichment were carried out using the Ion PGM $^{\mathrm{m}}$ Template OT2 200 Kit (Thermo Fisher Scientific, Carlsbad, CA, USA). The library was sequenced on the Ion PGM platform using the Ion PGM HiQ Sequencing Kit and Ion 314 Chip v2 (Thermo Fisher Scientific, Carlsbad, CA, USA). Sequenced reads were quality checked and trimmed using Ion Torrent Suite version 5.0.4 and assembled into contigs by de novo assembly, using the Genome Sequencer software version 2.9 (Roche, Basel, Switzerland). The contigs were compared to the GenBank non-redundant nucleotide database (BLASTn) to determine the contigs that represent the rotavirus

Table 2 Comparison of the genotype constellation of Slovenian RVA roe deer SLO/D110-15 with other RVA complete genome sequences from GenBank

\begin{tabular}{|c|c|c|c|c|c|c|c|c|c|c|c|c|}
\hline Strain & Origin & $\begin{array}{l}\text { VP7 } \\
\text { G }\end{array}$ & $\begin{array}{l}\text { VP4 } \\
{[\mathrm{P}]}\end{array}$ & $\begin{array}{l}\text { VP6 } \\
\text { I }\end{array}$ & $\begin{array}{l}\text { VP1 } \\
\mathrm{R}\end{array}$ & $\begin{array}{l}\text { VP2 } \\
\text { C }\end{array}$ & $\begin{array}{l}\text { VP3 } \\
\text { M }\end{array}$ & $\begin{array}{l}\text { NSP1 } \\
\text { A }\end{array}$ & $\begin{array}{l}\text { NSP2 } \\
\text { N }\end{array}$ & $\begin{array}{l}\text { NSP3 } \\
\mathrm{T}\end{array}$ & $\begin{array}{l}\text { NSP4 } \\
\text { E }\end{array}$ & $\begin{array}{l}\text { NSP5 } \\
\mathrm{H}\end{array}$ \\
\hline RVA/Human-wt/HUN/BP1879/2003/G6P[14] & $\mathrm{Hu}$ & 6 & 14 & 2 & 2 & 2 & 2 & 11 & 2 & 6 & 2 & 3 \\
\hline RVA/Human-wt/JAP/KF17/2010/G6P[9] & $\mathrm{Hu}$ & 6 & 9 & 2 & 2 & 2 & 2 & 3 & 2 & 3 & 3 & 3 \\
\hline RVA/Human-wt/ITA/PR1300/2004/G8P[14] & $\mathrm{Hu}$ & 8 & 14 & 2 & 2 & 2 & 2 & 3 & 2 & 6 & 2 & 3 \\
\hline RVA/Human-wt/HUN/182-02/2002/G8P[14] & $\mathrm{Hu}$ & 8 & 14 & 2 & 2 & 2 & 2 & 11 & 2 & 6 & 2 & 3 \\
\hline RVA/Human-wt/HUN/Hun5/1997/G6P[14] & $\mathrm{Hu}$ & 6 & 14 & 2 & 2 & 2 & 2 & 11 & 2 & 6 & 2 & 3 \\
\hline RVA/Human-wt/ITA/PR457/2009/G10P[14] & $\mathrm{Hu}$ & 10 & 14 & 2 & 2 & 2 & 2 & 11 & 2 & 6 & 2 & 3 \\
\hline RVA/Human-wt/ITA/PR1973/2009/G8P[14] & $\mathrm{Hu}$ & 8 & 14 & 2 & 2 & 2 & 2 & 3 & 2 & 6 & 2 & 3 \\
\hline RVA/Human-tc/EGY/AS970/2012/G8P[14] & $\mathrm{Hu}$ & 8 & 14 & 2 & 2 & 2 & 2 & 11 & 2 & 6 & 2 & 3 \\
\hline RVA/Human-WT/KEN/AK26/1982/G2P[4] & $\mathrm{Hu}$ & 2 & 4 & 2 & 2 & 2 & 2 & 2 & 1 & 2 & 2 & 2 \\
\hline RVA/Human-wt/MWI/1473/2001/G8P[4] & $\mathrm{Hu}$ & 8 & 4 & 2 & 2 & 2 & 2 & 2 & 2 & 2 & 2 & 2 \\
\hline RVA/Sheep-tc/ESP/OVR762/2002/G8P[14] & Ov & 8 & 14 & 2 & 2 & 2 & 2 & 11 & 2 & 6 & 2 & 3 \\
\hline RVA/Human-wt/BEL/B10925/1997/G6P[14] & $\mathrm{Hu}$ & 6 & 14 & 2 & 2 & 2 & 2 & 3 & 2 & 6 & 2 & 3 \\
\hline RVA/Human-wt/ITA/111-05-27/2005/G6P[14] & $\mathrm{Hu}$ & 6 & 14 & 2 & 2 & 2 & 2 & 3 & 2 & 6 & 2 & 3 \\
\hline RVA/Human-tc/GBR/A64/1987/G10P[14] & $\mathrm{Hu}$ & 10 & 14 & 2 & 2 & 2 & 2 & 3 & 2 & 6 & 2 & 3 \\
\hline RVA/Human-wt/HUN/BP1062/2004/G8P[14] & $\mathrm{Hu}$ & 8 & 14 & 2 & 2 & 2 & 2 & 11 & 2 & 6 & 2 & 3 \\
\hline RVA/Human-wt/BEL/B1711/2002/G6P[6] & $\mathrm{Hu}$ & 6 & 6 & 2 & 2 & 2 & 2 & 2 & 2 & 2 & 2 & 2 \\
\hline RVA/Human-tc/USA/DS-1/1976/G2P[4] & $\mathrm{Hu}$ & 2 & 4 & 2 & 2 & 2 & 2 & 2 & 2 & 2 & 2 & 2 \\
\hline RVA/Human-wt/THA/SKT-27/2012/G6P[14] & $\mathrm{Hu}$ & 6 & 14 & 2 & 2 & 2 & 2 & 3 & 2 & 6 & 2 & 3 \\
\hline RVA/Human-wt/BEL/B4106/2000/G3P[14] & $\mathrm{Hu}$ & 3 & 14 & 2 & 2 & 2 & 3 & 9 & 2 & 6 & 5 & 3 \\
\hline RVA/Human-wt/BEL/BE5028/2012/G3P[14] & $\mathrm{Hu}$ & 3 & 14 & 2 & 2 & 2 & 3 & 9 & 2 & 6 & 5 & 3 \\
\hline RVA/Rabbit-tc/ITA/30-96/1996/G3P[14] & $\mathrm{Rab}$ & 3 & 14 & 2 & 2 & 2 & 3 & 9 & 2 & 6 & 5 & 3 \\
\hline RVA/Human-tc/ITA/PA169/1988/G6P[14] & $\mathrm{Hu}$ & 6 & 14 & 2 & 2 & 2 & 2 & 3 & 2 & 6 & 2 & 3 \\
\hline RVA/Bovine-wt/JPN/Dai-10/2008/G24P[33] & Bo & 24 & 33 & 2 & 2 & 2 & 2 & 13 & 2 & 9 & 2 & 3 \\
\hline RVA/Human-tc/USA/Se584/1998/G6P[9] & $\mathrm{Hu}$ & 6 & 9 & 2 & 2 & 2 & 2 & 3 & 2 & 1 & 2 & 3 \\
\hline RVA/Human-wt/AUS/V585/2011/G10P[14] & $\mathrm{Hu}$ & 10 & 14 & 2 & 2 & 2 & 2 & 11 & 2 & 6 & 2 & 3 \\
\hline RVA/Human-tc/AUS/MG6/1993/G6P[14] & $\mathrm{Hu}$ & 6 & 14 & 2 & 2 & 2 & 2 & 11 & 2 & 6 & 2 & 3 \\
\hline RVA/Cow-wt/JPN/Tottori-SG/2013/G15P[14] & Bo & 15 & 14 & 2 & 2 & 2 & 2 & 3 & 2 & 6 & 2 & 3 \\
\hline RVA/Human-wt/GTM/2009726790/2009/G8P[14] & $\mathrm{Hu}$ & 8 & 14 & 2 & 2 & 2 & 2 & 13 & 2 & 6 & 2 & 3 \\
\hline RVA/Guanaco-wt/ARG/Chubut/1999/G8P[14] & $\mathrm{La}$ & 8 & 14 & 2 & 5 & 2 & 2 & 3 & 2 & 6 & 12 & 3 \\
\hline RVA/Cow-wt/ARG/B383/1998/G15P[11] & Bo & 15 & 11 & 2 & 5 & 2 & 2 & 13 & 2 & 6 & 12 & 3 \\
\hline RVA/Human-wt/AUS/RCH272/2012/G3P[14] & $\mathrm{Hu}$ & 3 & 14 & 2 & 3 & 3 & 3 & 9 & 2 & 6 & 2 & 3 \\
\hline RVA/Rabbit-tc/CHN/N5/1992/G3P[14] & $\mathrm{Rab}$ & 3 & 14 & 17 & 3 & 3 & 3 & 9 & 1 & 1 & 3 & 2 \\
\hline RVA/Vicuna-wt/ARG/C75/2010/G8P[14] & $\mathrm{Vi}$ & 8 & 14 & 2 & 2 & 2 & 2 & - & 2 & 6 & 3 & - \\
\hline RVA/Human-wt/US/2012841174/2012/G8P[14] & $\mathrm{Hu}$ & 8 & 14 & 1 & 1 & 1 & 1 & 8 & 1 & 1 & 1 & 1 \\
\hline RVA/Human-wt/BRB/2012821133/2012/G4P[14] & $\mathrm{Hu}$ & 4 & 14 & 1 & 1 & 1 & 1 & 8 & 1 & 1 & 1 & 1 \\
\hline RVA/Human-wt/USA/Wa/1974/G1P[8] & $\mathrm{Hu}$ & 1 & 8 & 1 & 1 & 1 & 1 & 1 & 1 & 1 & 1 & 1 \\
\hline RVA/roe_deer-wt/SLO/D38-14/2014/G6P[15] & Roe & 6 & 15 & 2 & 2 & 2 & 2 & 3 & 2 & 6 & 2 & 3 \\
\hline RVA/Roe deer-wt/SLO/D110-15/2015/G8P[14] & Roe & 8 & 14 & 2 & 2 & 2 & 2 & 3 & 2 & 6 & 2 & 3 \\
\hline
\end{tabular}


genome segments. To eliminate assembly errors, all sequenced reads were mapped against the concatenated segments of the assembled RVA strain SLO/D110-15 genome with the Genome Sequencer software version 2.9 (Roche). The Geneious software suite v 9.0.5 (Biomatters LtD, Auckland, New Zeland) was used for visualization and final data analysis. To obtain the genomic constellation of the RVA strain, the RotaC v 2.0 online automated genotyping tool [14] was used to assign the genotype of each genome segment.

\section{Phylogenetic analysis of the genome segments}

Selected sequences of RVA deposited in GenBank, with complete genome and genotype relevant to our strain, were used in the phylogenetic analyses. In addition, some of the most nearly identical sequences were added

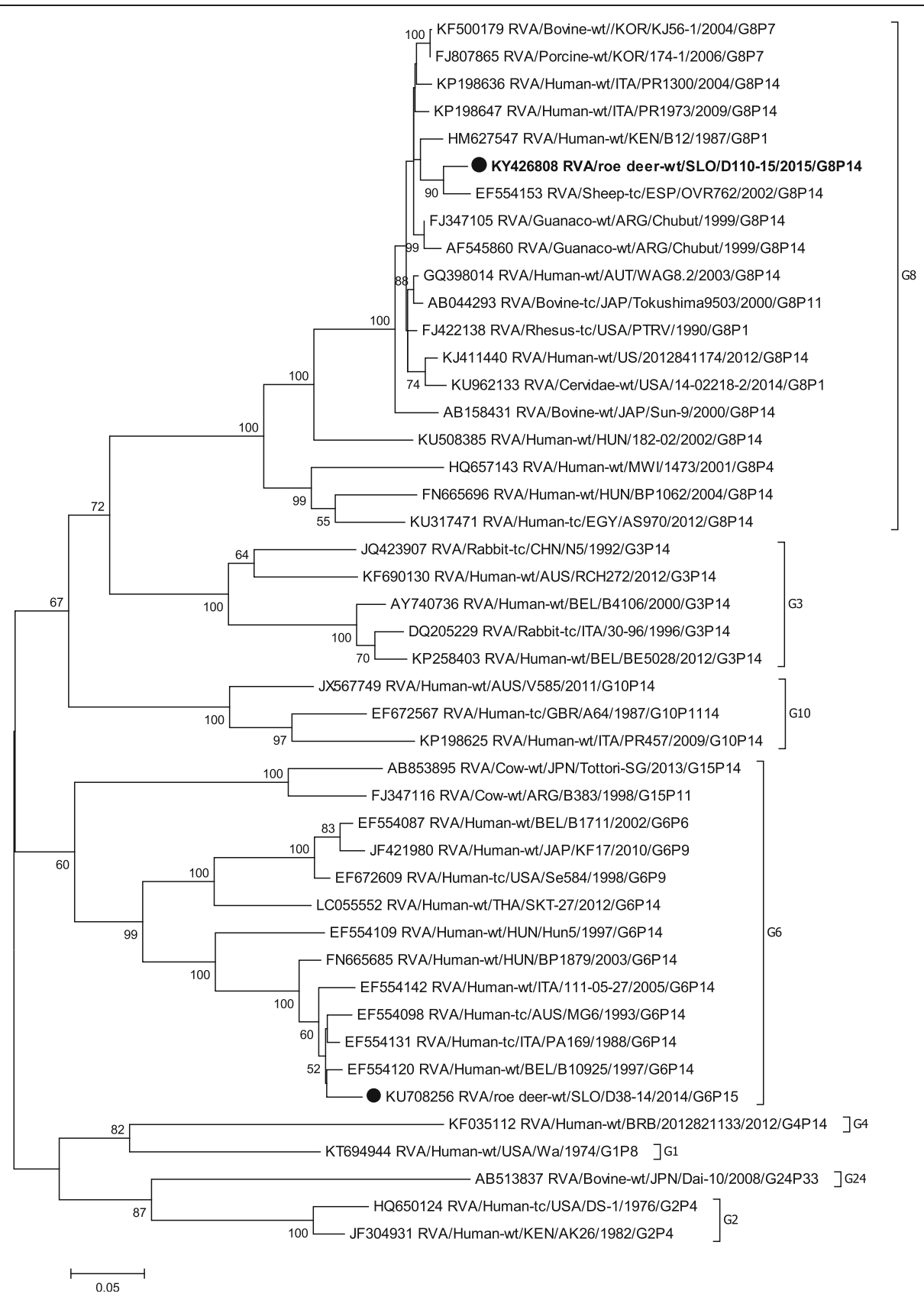

Fig. 1 The Maximum likelihood phylogenetic tree on VP7 segment. Bootstrap values lower than 50 are not shown. The Slovenian roe deer strains SLO/D110-15 and SLO/D38-14 are marked with circle. Roe deer strain SLO/D110-15 is highlighted in bold 
according to the BLAST search on each segment. The Slovenian RVA strain SI-2987/09, with genome profile G8$\mathrm{P}$ [14]-I2-R2-C2-M2-A3-N2-T6-E2-H3 was also included in the genome nucleotide sequence identity analysis (Table 1). The strain was detected in a child with gastroenteritis during the RVA survey in 2009 described in the study by Steyer et al. [15]. As the strain SI-2987/09 was available only with partial nucleotide sequences of the genome segments, it was not included in the phylogenetic analysis.

Nucleotides were aligned using ClustalW implemented in MEGA 7.0.21 [16]. Nucleotide identities were calculated according to the p-distances implemented in MEGA 7.0.21 [16]. Phylogenetic trees were constructed using the
Maximum-likelihood method based on the Kimura-2 parameter model. Branch statistics were calculated by bootstrap analysis of 1000 replicates.

\section{Results}

NGS analyses and construction of the complete genome sequence

The complete genome sequence of all 11 segments of the RVA/roe deer-wt/SLO/D110-15/2015/G8P[14] strain was obtained using the Ion Torrent PGM platform. The nucleotide sequences of all eleven genome segments were deposited in GenBank and are available under the following accession numbers: KY426809 (VP1), KY426810 (VP2), KY426811 (VP3), KY426812 (VP4), KY426813

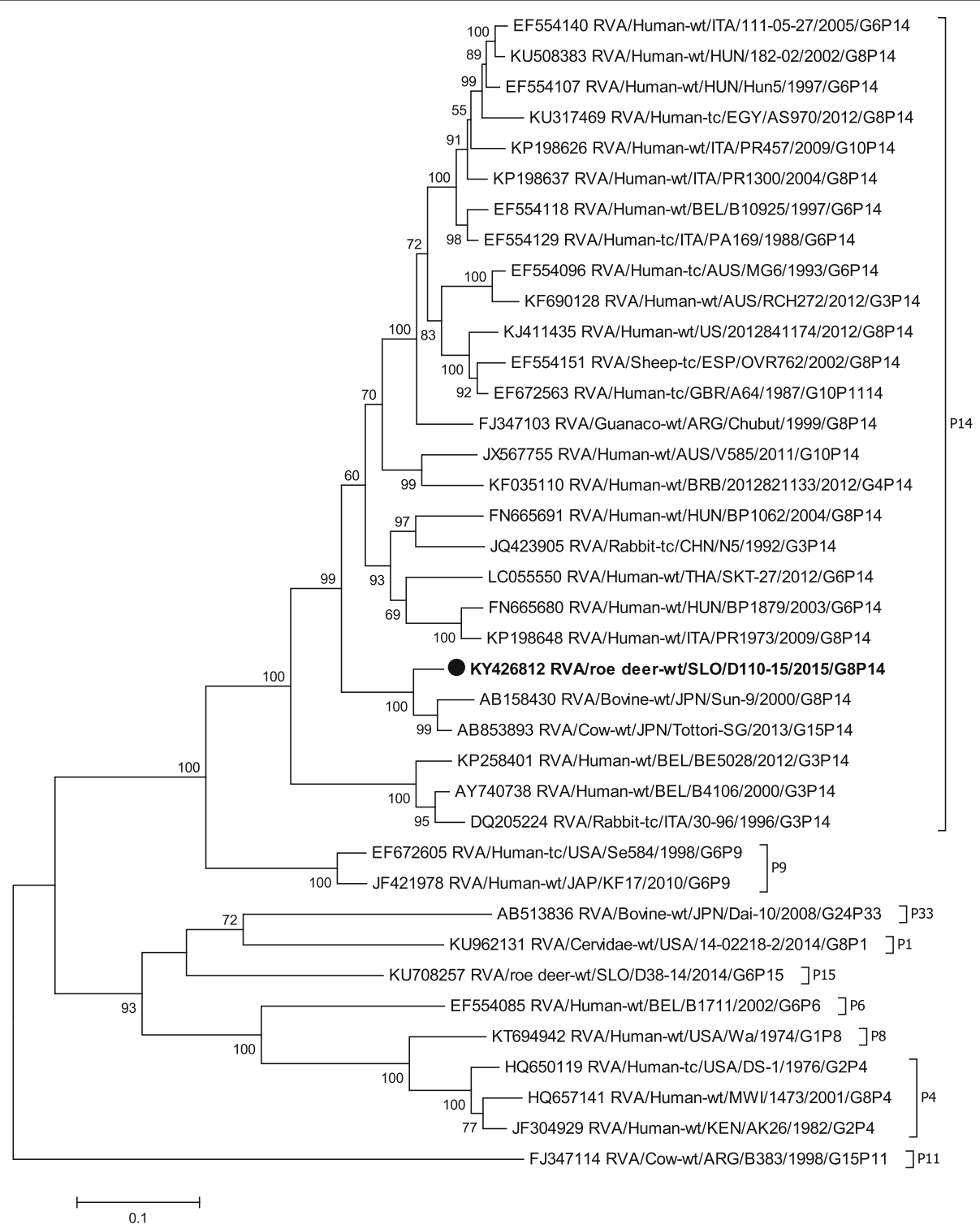

Fig. 2 The Maximum likelihood phylogenetic tree on VP4 segment. Bootstrap values lower than 50 are not shown. The Slovenian roe deer strains SLO/D110-15 and SLO/D38-14 are marked with circle. Roe deer strain SLO/D110-15 is highlighted in bold 
(VP6), KY426808 (VP7), KY426803 (NSP1), KY426804 (NSP2), KY426805 (NSP3), KY426806 (NSP4) and KY426807 (NSP5 and NSP6).

In total, 98,441 reads were generated and 25 large contigs (lengths $>500 \mathrm{nt}$ ) obtained by de novo assembly. The BLAST search revealed that 11 of the contigs belong to the 11 RVA genome segments and constituted the complete genome of the RVA strain SLO/ D110-15. Mapping against the concatenated segments of the RVA strain SLO/D110-15 genome resulted in 66,153 mapped reads (81.4\% of all reads) with an average depth of 569.6 and average map length of 158 nt. Using the RotaC classification tool, the whole genome constellation of the RVA strain SLO/D110-15 was determined to be G8-P[14]-I2-R2-C2-M2-A3-N2T6-E2-H3. The complete genotype constellation of the SLO/D110-15 strain was compared with those of RVA G8P[14] strains and other representative strains from humans and animals (Table 2). The genotype constellation of the SLO/D110-15 strain was identical to those of the two Italian human strains ITA/PR1300 and ITA/PR1973, and of the Slovenian human strain

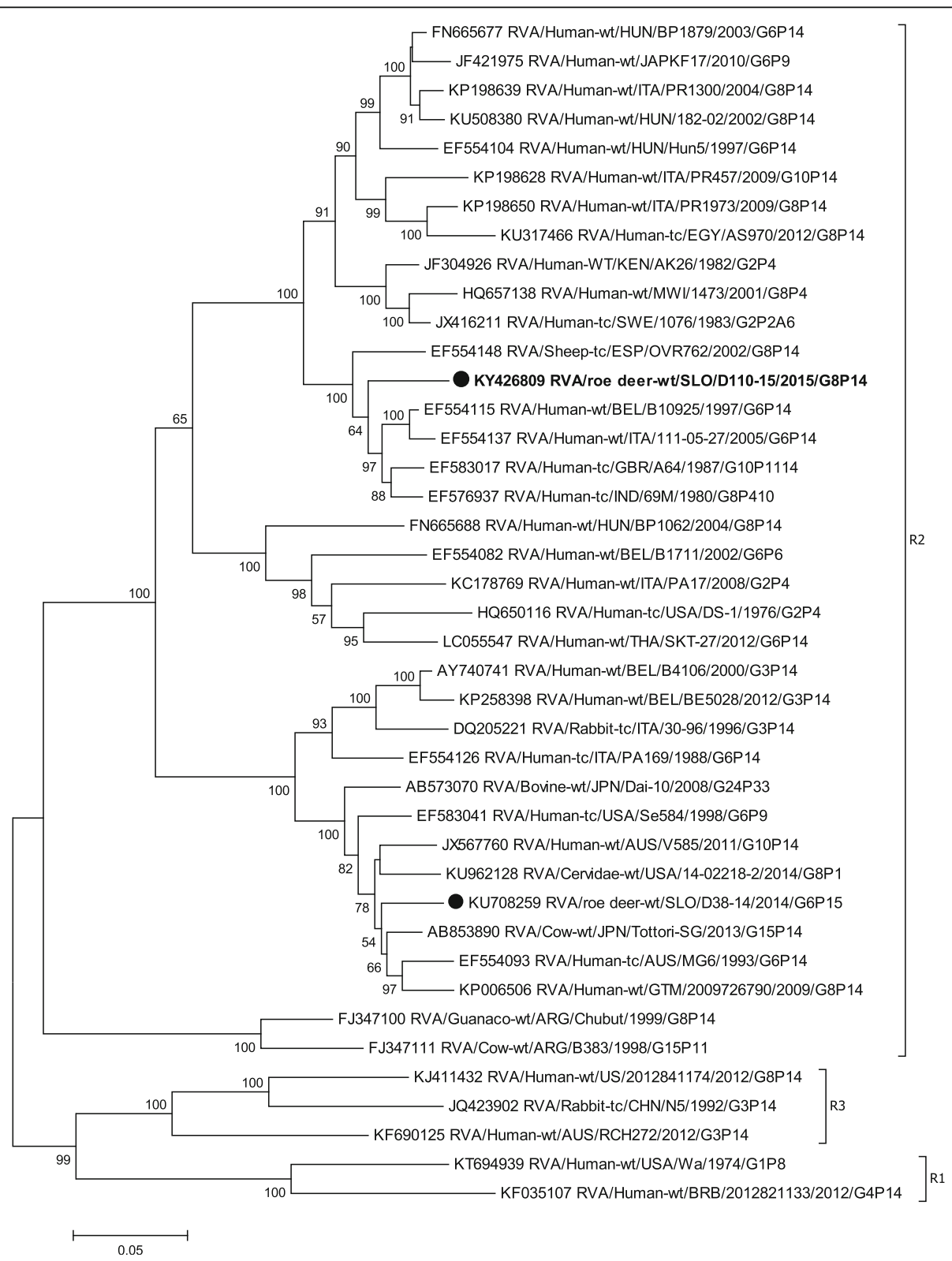

Fig. 3 The Maximum likelihood phylogenetic tree on VP1 segment. Bootstrap values lower than 50 are not shown. The Slovenian roe deer strains SLO/D110-15 and SLO/D38-14 are marked with circle. Roe deer strain SLO/D110-15 is highlighted in bold 
SI-2987/09, namely G8-P[14]-I2-R2-C2-M2-A3-N2T6-E2-H3.

\section{Nucleotide sequence identity and phylogenetic analysis of the genome segments}

p-Distances were calculated for each of the 11 segments of SLO/D110-15 and for selected strains from GenBank. The highest level of nucleotide identity, 99.7\%, was observed on the NSP5 segment with strain BEL/ BEF06018 and on the NSP1 segment with strain SI$2987 / 09$. The lowest nucleotide identity was $92.3 \%$ and was observed on the VP2 segment with strain HUN/ 182-02 (Table 1). The roe deer SLO/D110-15 and human SI-2987/09 strains shared fewer than $90 \%$ nucleotide identities for partial sequences of structural genes VP1, VP6, VP7 and fragment VP8* of the VP4 gene,

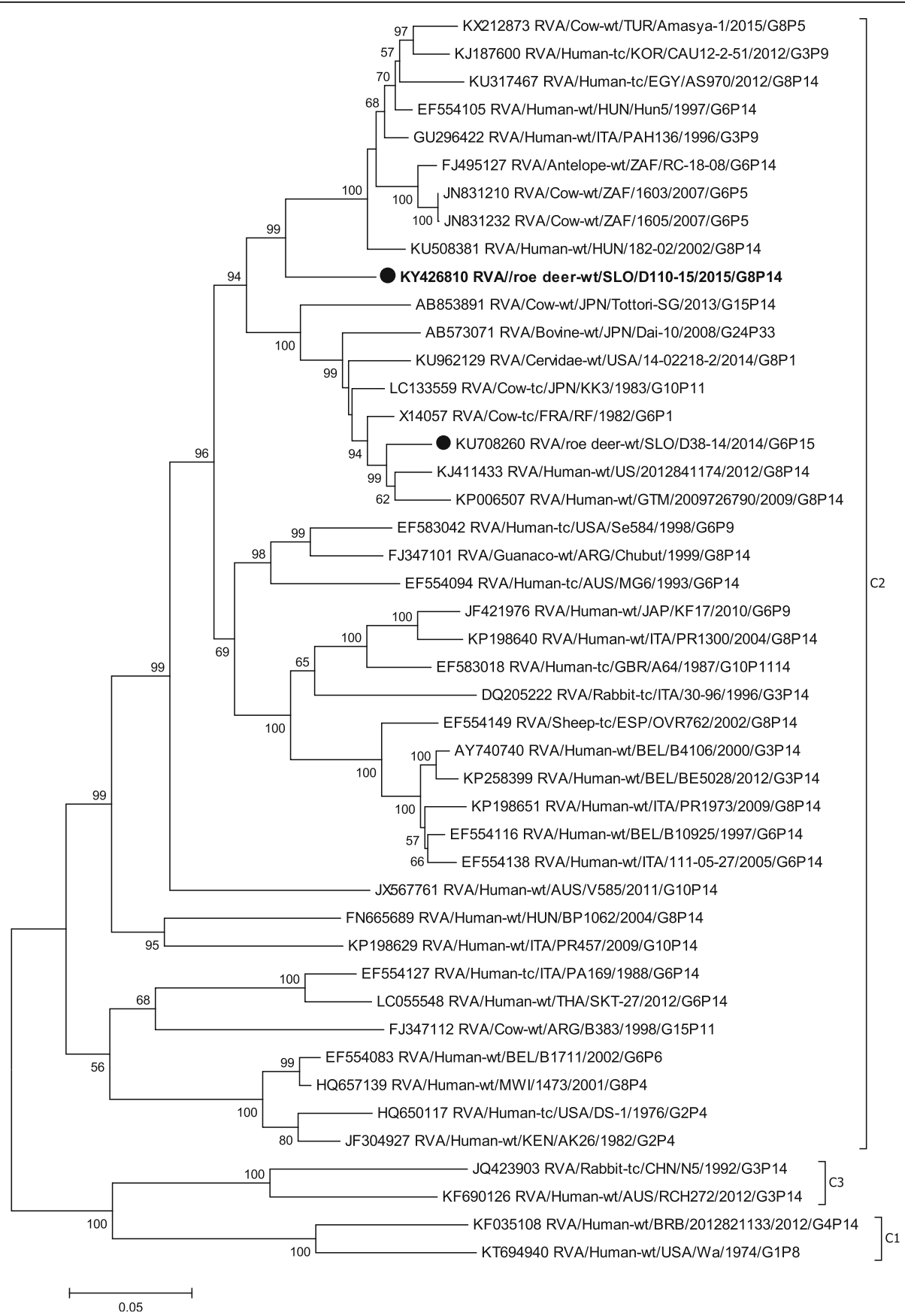

Fig. 4 The Maximum likelihood phylogenetic tree on VP2 segment. Bootstrap values lower than 50 are not shown. The Slovenian roe deer strains SLO/D110-15 and SLO/D38-14 are marked with circle. Roe deer strain SLO/D110-15 is highlighted in bold 
although sharing the same genotype. In contrast, the partial sequences of the non-structural protein genes shared higher degrees of identity, ranging from 93.1\% to $99.7 \%$.

In the VP7 phylogenetic tree, the strain SLO/D110-15 was most closely related to the Spanish ovine strain ESP/OVR762, with a nucleotide identity of $96.6 \%$
(Table 1, Fig. 1) and, when compared to other G8 strains, the lowest nucleotide identity of $81.8 \%$. Comparison of the VP7 segment with the other known roe deer sample, RVA SLO/D38-14, led to an identity of $85.8 \%$.

Phylogenetic analysis of the VP4 gene showed that the strain SLO/D110-15 formed a cluster with the Japanese

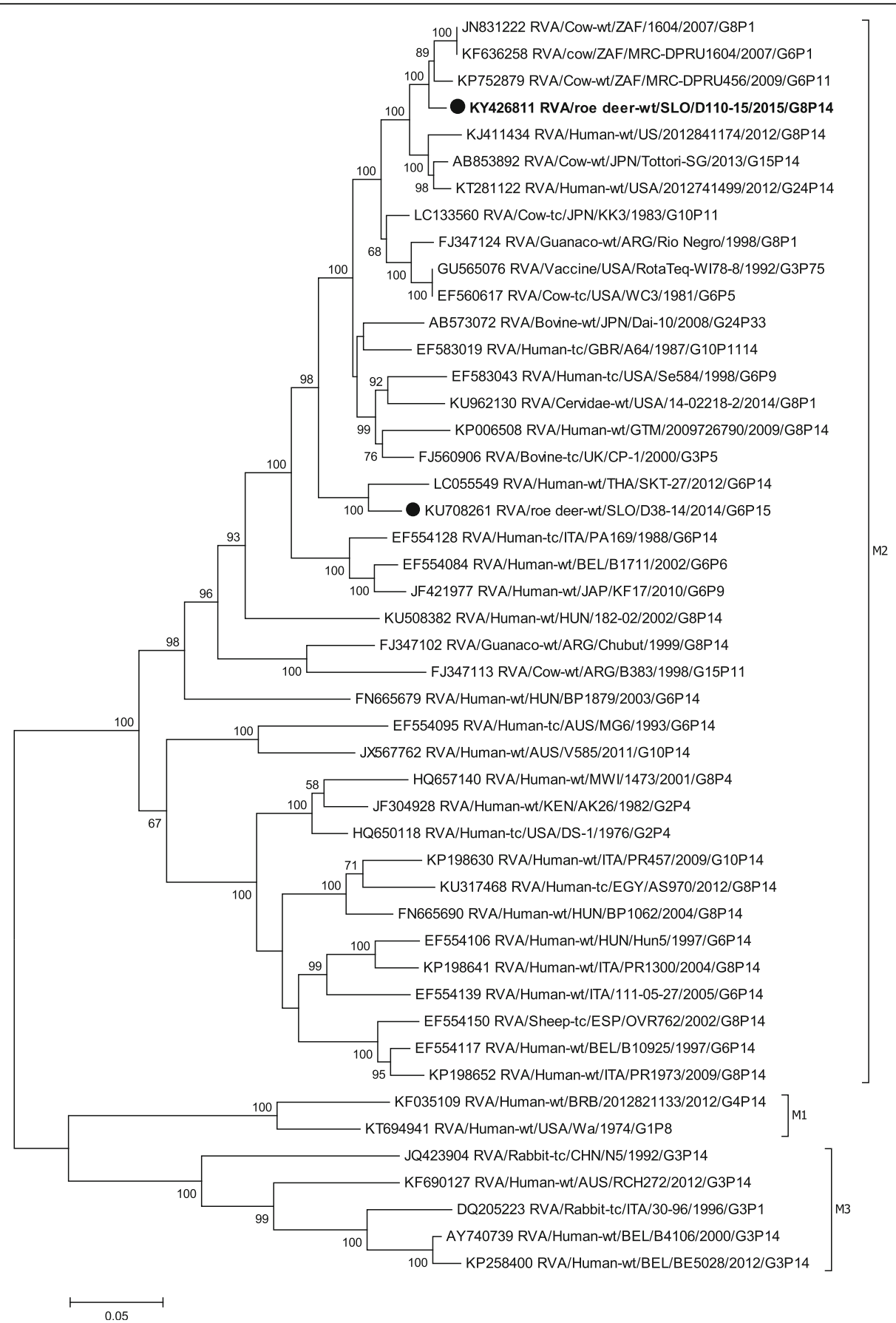

Fig. 5 The Maximum likelihood phylogenetic tree on VP3 segment. Bootstrap values lower than 50 are not shown. The Slovenian roe deer strains SLO/D110-15 and SLO/D38-14 are marked with circle. Roe deer strain SLO/D110-15 is highlighted in bold 
$\mathrm{P}$ [14] bovine strains JPN/Tottori-SG and JPN/Sun9, with nucleotide identities of $94.8 \%$ and $93.2 \%$, respectively (Table 1, Fig. 2). The lowest degree of nucleotide identity, when compared with other P[14] strains, was $80.9 \%$. On the VP4 segment the nucleotide identity between roe deer RVA SLO/D110-15 and SLO/D38-14 was, as expected, low (67.3\%), as they represent different $\mathrm{P}$ genotypes.

Phylogenetic analysis of VP1-VP3, VP6 and NSP1NSP5 gene segments revealed that the SLO/D110-15 strain clusters with bovine and bovine-like RVA strains, sharing the same non-G/P genotype constellation (genetic backbone) I2-R2-C2-M2-A3-N2-T6-E2-H3 (Table 2) and with the highest degree of nucleotide identity in the range of $92.2 \%$ to $99.7 \%$ (Table 1, Figs. 3, 4, 5, 6, 7, $8,9,10$ and 11).

When comparing segments from the backbone of roe deer SLO/D110-15 with those of roe deer SLO/D38-14, the highest degree of nucleotide identity ranged only from $85.8 \%$ to $96.8 \%$, even though they share the same genetic backbone.

\section{Discussion}

There are only two reports describing the complete genome constellation of RVA in deer. The first detection and complete genome characterization of a roe deer rotavirus was in 2015 [12]. Here, we describe the second detection of RVA in roe deer and the first RVA strain with the G8-P[14]-I2-R2-C2-M2-A3-N2-T6-E2-H3 genotype constellation. Important insights into the complete genetic makeup of a deer rotavirus strain are provided in this report and consequently new knowledge about the host range for this RVA genotype, together with their strain diversity.

The sequencing result of the SLO/D110-15 roe deer sample investigated in this study revealed a large

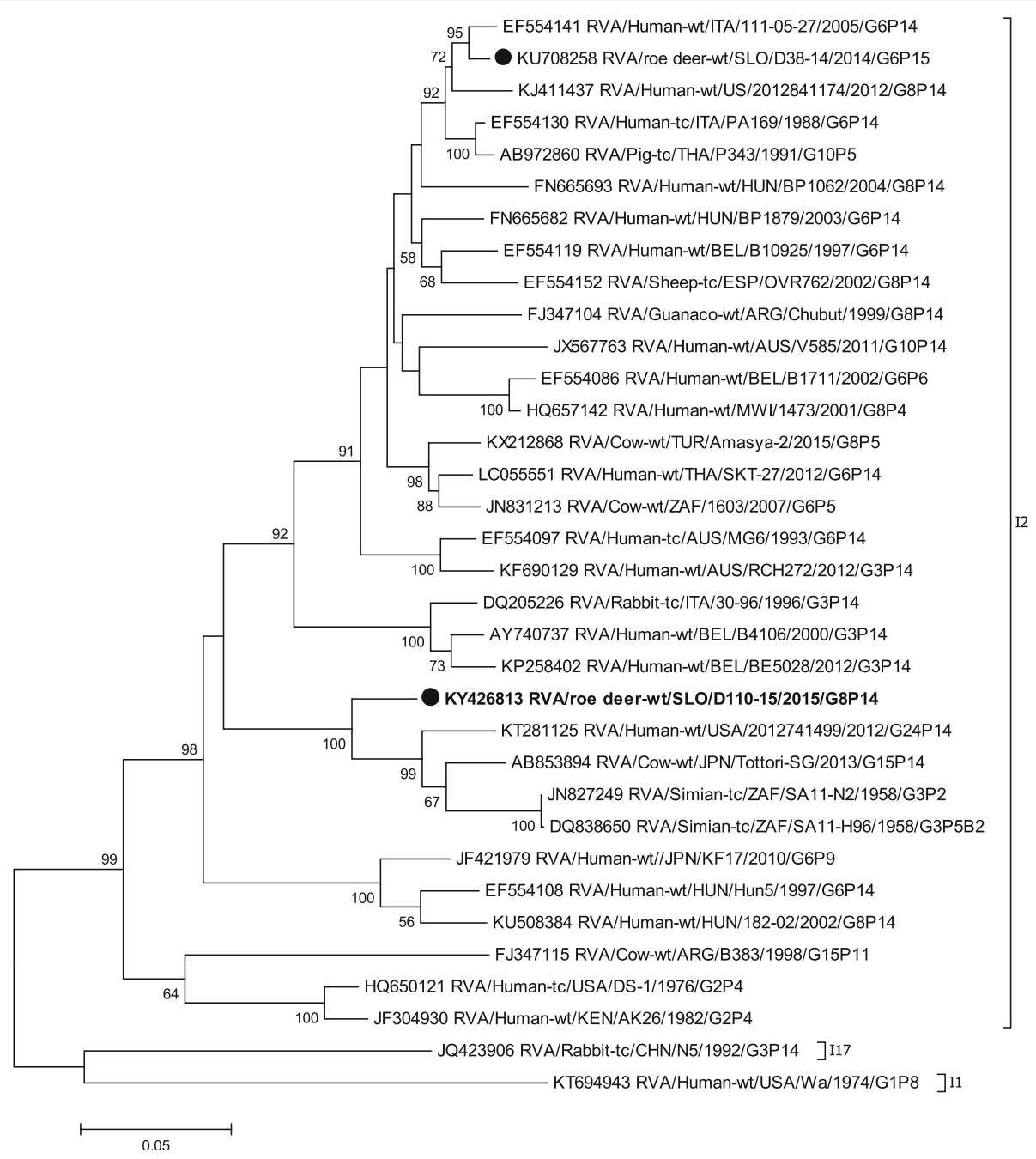

Fig. 6 The Maximum likelihood phylogenetic tree on VP6 segment. Bootstrap values lower than 50 are not shown. The Slovenian roe deer strains SLO/D110-15 and SLO/D38-14 are marked with circle. Roe deer strain SLO/D110-15 is highlighted in bold 


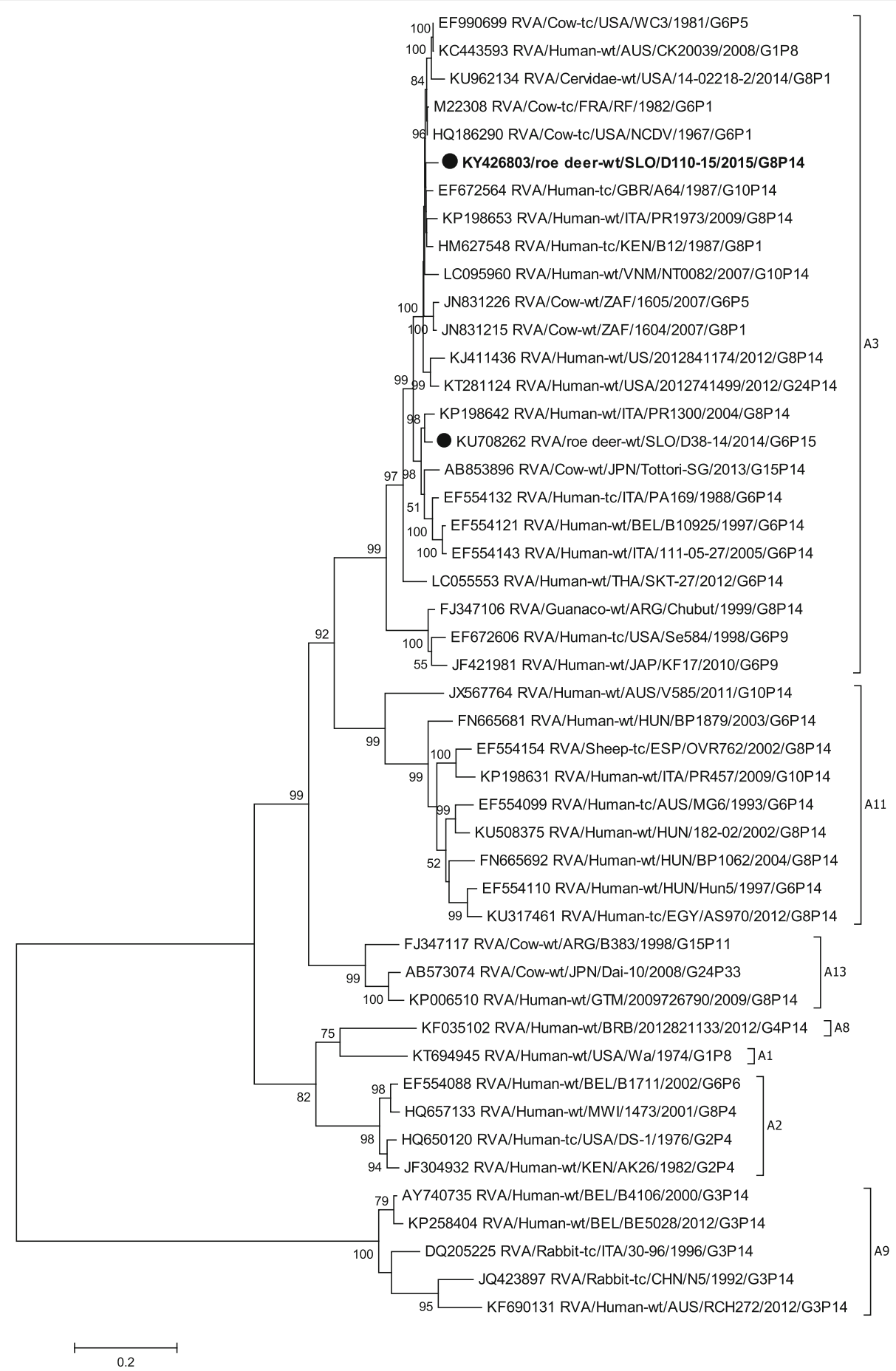

Fig. 7 The Maximum likelihood phylogenetic tree on NSP1 segment. Bootstrap values lower than 50 are not shown. The Slovenian roe deer strains SLO/D110-15 and SLO/D38-14 are marked with circle. Roe deer strain SLO/D110-15 is highlighted in bold

number of RVA sequencing reads (81.4\% of all sequencing reads), using an unbiased protocol for sample and library preparation, and with no observed clinical signs in the respective animal. The NGS analyses show that, unlike the first positive roe deer sample collected in 2014 in Slovenia, SLO/D38-14, that belongs to the G6P[15] genotype, the roe deer sample SLO/D110-15 belongs to the G8P[14] genotype. They share from $67.3 \%$ to $96.8 \%$ genome segment nucleotide identity. 


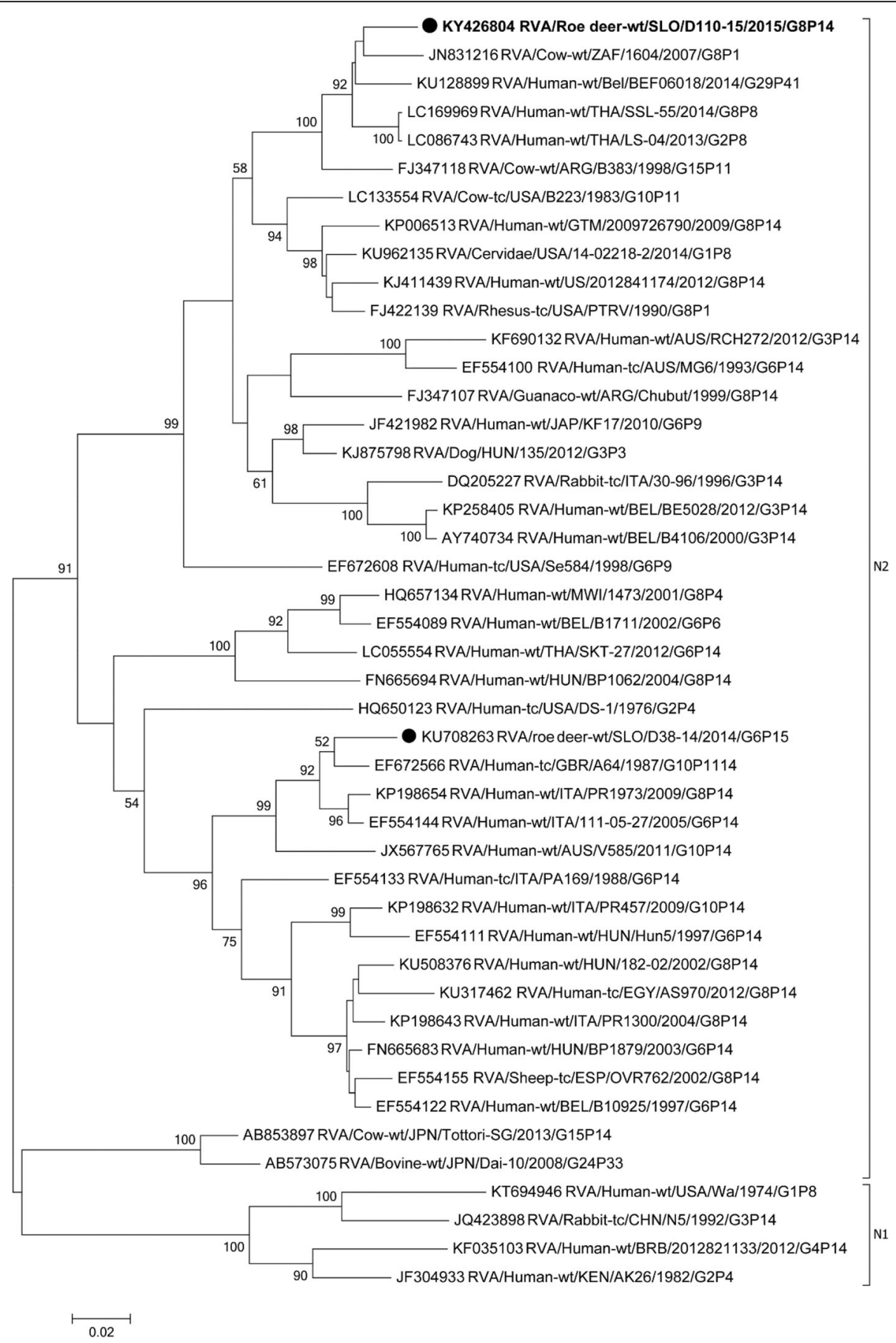

Fig. 8 The Maximum likelihood phylogenetic tree on NSP2 segment. Bootstrap values lower than 50 are not shown. The Slovenian roe deer strains SLO/D110-15 and SLO/D38-14 are marked with circle. Roe deer strain SLO/D110-15 is highlighted in bold

The strain SLO/D110-15 has the typical bovine DS1-like genetic backbone found in cattle and other animals from the order Artiodactyla together with a G/P combination also found in zoonotic human RVA strains. Detailed phylogenetic analysis of the 11 genome segments revealed the closest relatedness of the
SLO/D110-15 strain to RVA strains having the bovine-like genotype constellation from humans and animals.

RVA strains of the G8P[14] genotype, combined with the bovine DS1-like genetic backbone, are detected sporadically in cattle, sheep, guanaco, vicuna and in 


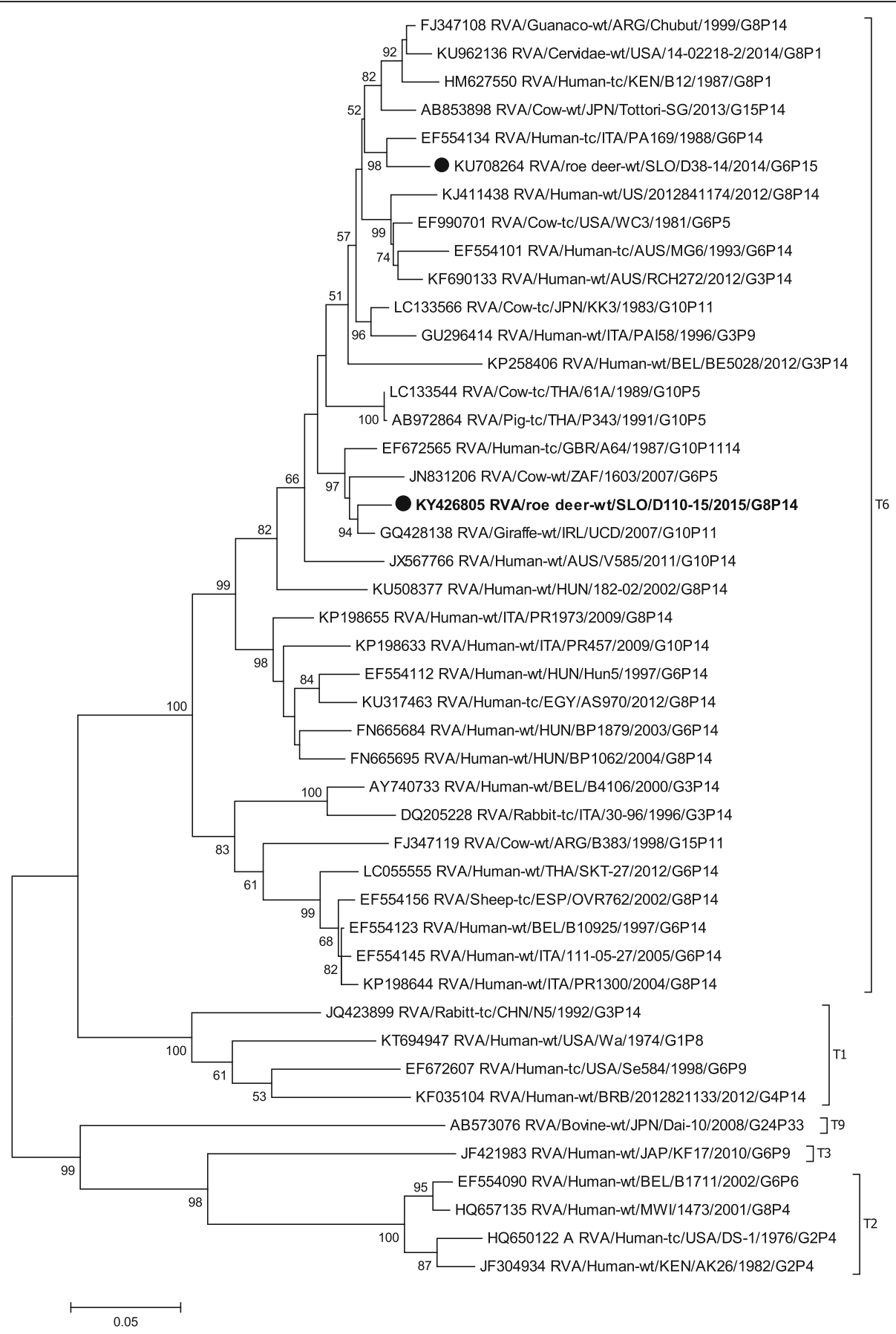

Fig. 9 The Maximum likelihood phylogenetic tree on NSP3 segment. Bootstrap values lower than 50 are not shown. The Slovenian roe deer strains SLO/D110-15 and SLO/D38-14 are marked with circle. Roe deer strain SLO/D110-15 is highlighted in bold

humans [17-23]. It was suggested that the $\mathrm{P}[14]$ genotypes are less virulent for the ruminant host species, and thus more probably shed by animals with subclinical infections [20]. This was supported by our finding that the SLO/D110-15 was detected in an animal without evident clinical signs. However, the real pathogenic potential of these rotaviruses still has to be explored. Virus isolation in MA104 cell line was attempted for the strain SLO/D110-15 but was not successful, even after three passages.

The original source of RVA strains with G8P[14] genotype most probably includes multiple human to animal 


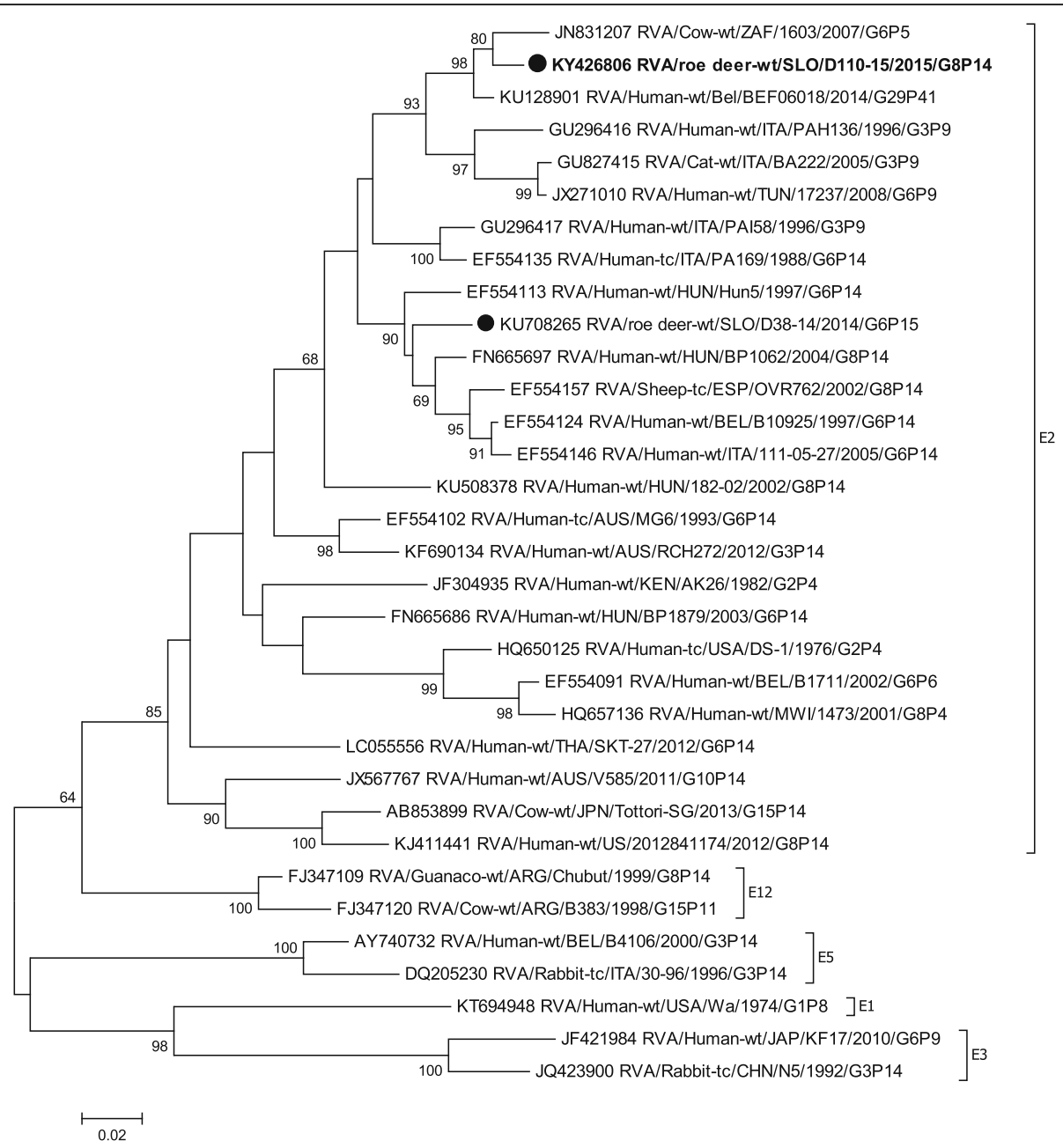

Fig. 10 The Maximum likelihood phylogenetic tree on NSP4 segment. Bootstrap values lower than 50 are not shown. The Slovenian roe deer strains SLO/D110-15 and SLO/D38-14 are marked with circle. Roe deer strain SLO/D110-15 is highlighted in bold

and animal to human transmission events [24]. It has been proposed that human $\mathrm{P}[14]$ strains are derived from interspecies transmission of RVA from humans and ungulates [17]. Other studies suggest zoonotic transmissions of the G8P[14] RVA strains with the bovine DS1-like genetic backbone [20]. Two human strains from Italy, PR1300 and PR1973 have a full genome constellation identical to that of our roe deer strain (G8-P[14]-I2-R2-C2-M2-A3-N2-T6-E2-H3) [19]. For these two human strains it was suggested that they are zoonotic and transmitted to humans from an animal belonging to the order Artiodactyla [19]. In addition, one G8P[14] strain with a genotype constellation identical to that of the roe deer strain, was observed in a child with gastroenteritis during the RVA survey in Slovenia in 2009 [15]. Although the genome segment sequences of this RVA human strain are not complete, it was shown that human and roe deer strains from Slovenia are not closely related as the VP8* fragment and partial VP7 nucleotide sequence identities were both less than 90\%. Relatively low identities between these two strains were shown also for other genes coding for structural proteins. For genes coding non-structural proteins the identities were much higher, indicating the reassortant nature of G8P[14], probably as a result of circulating in different hosts. Solving the riddle of the evolutionary path of G8P[14] strains requires the analysis of many more strains. Surveillance of the RVA in animals and humans should be continued to gain a clearer molecular and epidemiological history of zoonotic RVA strains.

\section{Conclusions}

The G8P[14] genotype has been found, for the first time, in deer, a newly described host from the order Artiodactyla for this RVA genotype. The finding of a RVA strain with the same genome segment constellation in humans indicates the possible zoonotic potential of this virus strain. 


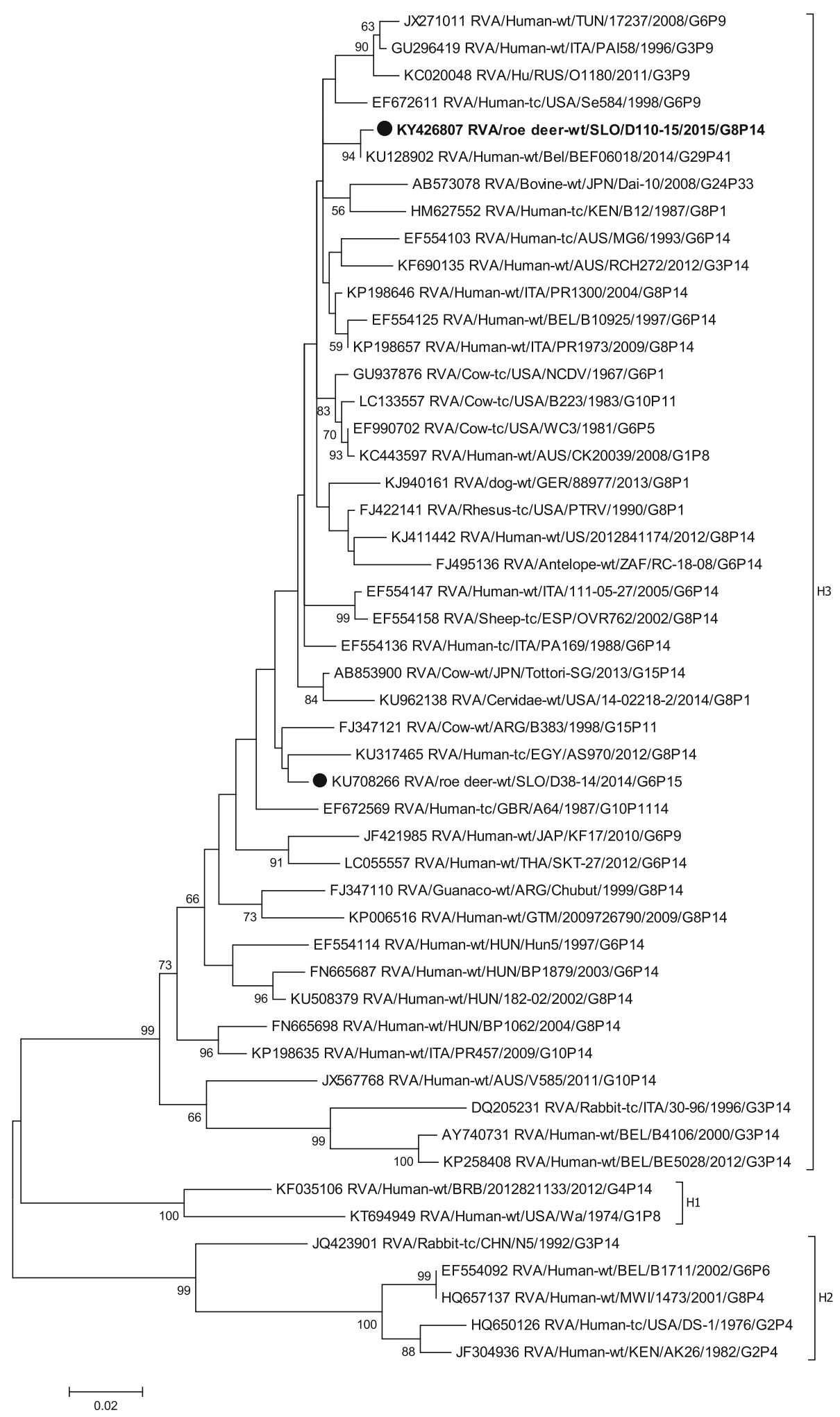

Fig. 11 The Maximum likelihood phylogenetic tree on NSP5/NSP6 segment. Bootstrap values lower than 50 are not shown. The Slovenian roe deer strains SLO/D110-15 and SLO/D38-14 are marked with circle. Roe deer strain SLO/D110-15 is highlighted in bold 


\section{Abbreviations}

NGS: next generation sequencing technology; RCWG: Rotavirus Classification Working Group; RVA: Group A rotaviruses

\section{Acknowledgements}

Not applicable.

\section{Competing interests}

We declare no competing interests, financial or otherwise.

\section{Funding}

This work was supported by the Slovenian Ministry for Higher Education, Science and Technology (Research program P4-0092).

\section{Availability of data and materials}

All data generated or analysed during this study are included in this published article. All the materials are stored in the Institute of Food safety, feed and environment, Veterinary Faculty, University of Ljubljana, Slovenia. Nucleotide sequences are deposited in GenBank.

\section{Authors' contributions}

UJC processed faecal sample and isolated RNA. UK performed the NGS and analysed the results. UJC, UK, AS and AK performed the phylogenetic analysis on all 11 segments of the RVA. All authors contributed in writing the manuscript. All authors read and approved the final manuscript.

\section{Consent for publication}

The manuscript contains no individual person's data and does not require consent for publication.

\section{Ethics approval}

Ethics approval was not required as only roe deer faeces not live animals were involved.

\section{Publisher's Note}

Springer Nature remains neutral with regard to jurisdictional claims in published maps and institutional affiliations.

\section{Author details}

${ }^{1}$ Institute of Food safety, Feed and Environment, Veterinary Faculty, University of Ljubljana, Gerbičeva 60, 1000 Ljubljana, Slovenia. ${ }^{2}$ Institute of Microbiology and Parasitology, Veterinary Faculty, University of Ljubljana, Gerbičeva 60, 1000 Ljubljana, Slovenia. ${ }^{3}$ Institute of Microbiology and Immunology, Faculty of Medicine, University of Ljubljana, Zaloška 4, 1000 Ljubljana, Slovenia.

\section{Received: 18 May 2017 Accepted: 16 November 2017}

Published online: 25 November 2017

\section{References}

1. Schiff LA, Nibert ML, Tyler KL: Orthoreoviruses and their replication. In: Fields virology. 5th edn. Edited by Knipe DM, Howley PM, Griffin DE, Lamb RA, Martin MA, Roizman B, Straus SE. Philadelphia: Lippincott, Williams \&amp; Wilkins; 2007: 1854-1915.

2. Estes MK, Greenberg HB: Rotaviruses. In: Fields virology. 6th edn. Edited by Fields BN, Knipe DM, Howley PM. Philadelphia: Lippincott, Williams \& Wilkins; 2013: 1347-1401

3. Martella V, Bányai K, Matthijnssens J, Buonavoglia C, Ciarlet M. Zoonotic aspects of rotaviruses. Vet Microbiol. 2010;140(3-4):246-55.

4. Matthijnssens J, Taraporewala ZF, Yang H, Rao S, Yuan L, Cao D, Hoshino Y, Mertens PP, Carner GR, McNeal M, et al. Simian rotaviruses possess divergent gene constellations that originated from interspecies transmission and reassortment. J Virol. 2010;84(4):2013-26.

5. Li K, Lin XD, Huang KY, Zhang B, Shi M, Guo WP, Wang MR, Wang W, Xing JG $\mathrm{Li} \mathrm{MH}$, et al. Identification of novel and diverse rotaviruses in rodents and insectivores, and evidence of cross-species transmission into humans. Virology. 2016;494:168-77

6. Matthijnssens J, Ciarlet M, Rahman M, Attoui H, Bányai K, Estes MK, Gentsch JR, Iturriza-Gómara M, Kirkwood CD, Martella V, et al. Recommendations for the classification of group a rotaviruses using all 11 genomic RNA segments. Arch Virol. 2008;153(8):1621-9.
7. Matthijnssens J, Ciarlet M, McDonald SM, Attoui H, Bányai K, Brister JR, Buesa J, Esona MD, Estes MK, Gentsch JR, et al. Uniformity of rotavirus strain nomenclature proposed by the rotavirus classification working group (RCWG). Arch Virol. 2011;156(8):1397-413.

8. Matthijnssens J, Ciarlet M, Heiman E, Arijs I, Delbeke T, McDonald SM, Palombo EA, Iturriza-Gómara M, Maes P, Patton JT, et al. Full genome-based classification of rotaviruses reveals a common origin between human Wa-like and porcine rotavirus strains and human DS-1-like and bovine rotavirus strains. J Virol. 2008;82(7):3204-19.

9. Steyer A, Poljsak-Prijatelj M, Barlic-Maganja D, Marin J. Human, porcine and bovine rotaviruses in Slovenia: evidence of interspecies transmission and genome reassortment. J Gen Virol. 2008;89(Pt 7):1690-8.

10. Ghosh S, Kobayashi N. Whole-genomic analysis of rotavirus strains: current status and future prospects. Future Microbiol. 2011;6(9):1049-65.

11. Ghosh S, Kobayashi N. Exotic rotaviruses in animals and rotaviruses in exotic animals. Virusdisease. 2014;25(2):158-72.

12. Jamnikar-Ciglenecki U, Kuhar U, Sturm S, Kirbis A, Racki N, Steyer A. The first detection and whole genome characterization of the G6P[15] group a rotavirus strain from roe deer. Vet Microbiol. 2016;191:52-9.

13. Anbalagan S, Peterson J. Detection and whole-genome characterization of a G8P[1] group a rotavirus strain from deer. Genome Announc. 2016;4(6)

14. Maes P, Matthijnssens J, Rahman M, Van Ranst M. RotaC: a web-based tool for the complete genome classification of group a rotaviruses. BMC Microbiol. 2009;9:238.

15. Steyer A, Sagadin M, Kolenc M, Poljsak-Prijatelj M. Molecular characterization of rotavirus strains from pre- and post-vaccination periods in a country with low vaccination coverage: the case of Slovenia. Infect Genet Evol. 2014;28:413-25.

16. Kumar S, Stecher G, Tamura K. MEGA7: molecular evolutionary genetics analysis version 7.0 for bigger datasets. Mol Biol Evol. 2016;33(7):1870-4

17. Matthijnssens J, Potgieter CA, Ciarlet M, Parreño V, Martella V, Bányai K, Garaicoechea L, Palombo EA, Novo L, Zeller M, et al. Are human P[14] rotavirus strains the result of interspecies transmissions from sheep or other ungulates that belong to the mammalian order Artiodactyla? J Virol. 2009; 83(7):2917-29.

18. Bányai K, Papp H, Dandár E, Molnár P, Mihály I, Van Ranst M, Martella V, Matthijnssens J. Whole genome sequencing and phylogenetic analysis of a zoonotic human G8P[14] rotavirus strain. Infect Genet Evol. 2010;10(7):1140-4.

19. Medici MC, Tummolo F, Bonica MB, Heylen E, Zeller M, Calderaro A, Matthijnssens J. Genetic diversity in three bovine-like human G8P[14] and G10P[14] rotaviruses suggests independent interspecies transmission events. J Gen Virol. 2015;96(Pt 5):1161-8.

20. Marton S, Dóró R, Fehér E, Forró B, Ihász K, Varga-Kugler R, Farkas SL, Bányai K. Whole genome sequencing of a rare rotavirus from archived stool sample demonstrates independent zoonotic origin of human G8P[14] strains in Hungary. Virus Res. 2017;227:96-103.

21. Badaracco A, Matthijnssens J, Romero S, Heylen E, Zeller M, Garaicoechea L, Van Ranst M, Parreño V. Discovery and molecular characterization of a group a rotavirus strain detected in an Argentinean vicuña (Vicugna Vicugna). Vet Microbiol. 2013;161(3-4):247-54.

22. Gautam R, Mijatovic-Rustempasic S, Roy S, Esona MD, Lopez B, Mencos Y, Rey-Benito G, Bowen MD. Full genomic characterization and phylogenetic analysis of a zoonotic human G8P[14] rotavirus strain detected in a sample from Guatemala. Infect Genet Evol. 2015;33:206-11.

23. Ciarlet M, Estes M, Britton G: Rotaviruses: basic biology, epidemiology and methodologies. In: Encyclopedia of environmental microbiology. Edn. New York: John Wiley \&amp; Sons; 2002

24. Swiatek DL, Palombo EA, Lee A, Coventry MJ, Britz ML, Kirkwood CD. Characterisation of G8 human rotaviruses in Australian children with gastroenteritis. Virus Res. 2010;148(1-2):1-7. 